\title{
EL CLERO SECULAR EN NAVARRA A MEDIADOS DEL SIGLO XIII
}

\author{
POR \\ María Raquel García Arancón \\ Universidad de Navarra
}

\section{Resumen}

Este artículo ofrece una aproximación de conjunto a la vida del clero secular en Navarra. Los datos obtenidos ofrecen un interesante muestreo para el estudio del régimen interno y la administración de los cabildos, y revelan que, aunque no juegan un papel relevante, sus actividades y vida económica no están estancados.

\begin{abstract}
The author offers an study about the clergy's secular life in Navarra. The informations help us to analyze the internal regime and the administration of the chapters, and show us, in spite of they do not play a relevant role, their activities and economic life were not stopped.
\end{abstract}

Una rápida visión de conjunto de las referencias documentales conservadas revela que, a mediados del siglo XIII, la vida de las instituciones religiosas en Navarra era floreciente. Los viejos establecimientos monásticos de los siglos XI y XII, que habían conocido una extraordinaria pujanza, ven estancada su influencia y dominio territorial. Mientras tanto en las villas más importantes del reino surgen múltiples casas de dominicos, franciscanos y clarisas. El propio tey Teobaldo II (1253-1270), siguiendo la corriente espiritual del momento, funda varios conventos y favorece con largueza a otros. 
Dentro del clero es, pues, el secular, el sector menos conocido y el que parece tener menor peso específico. Me ha parecido útil dejar constancia de que, aunque no juegue un papel relevante, sus actividades y vida económica no están fosilizadas .Los datos analizados, junto a privilegios papales y limosnas regias, ofrecen un interesante muestreo para el estudio del régimen interno y la administración de estos cabildos .Además, en iglesias locales, se detecta una acusada tendencia a vincularlas al patronato de la Corona.

\section{LOS CABILDOS DE LAS CATEDRALES}

a) La catedral de Pamplona

Entre 1242 y 1266 la vida de la sede episcopal está presidida por la vigorosa personalidad de don Pedró Jiménez de Gazolaz. Las relaciones entre este prelado y el rey Teobaldo II, así como la actuación del primero y de su sucesor don Armingot (1268-1277), se han puesto ya de relievel. Aquí reseñaré únicamente los privilegios concedidos a la catedral en este momento.

No se conserva ningún documento expedido por Teobaldo II, quizá porque las difíciles relaciones entre la corona y la mitra no propiciaban privilegios de índole económica. Sin embargo el soberano, que había jurado mantener los fueros de la Iglesia navarra ${ }^{2}$, y que quizá se coronó rey en la cate-

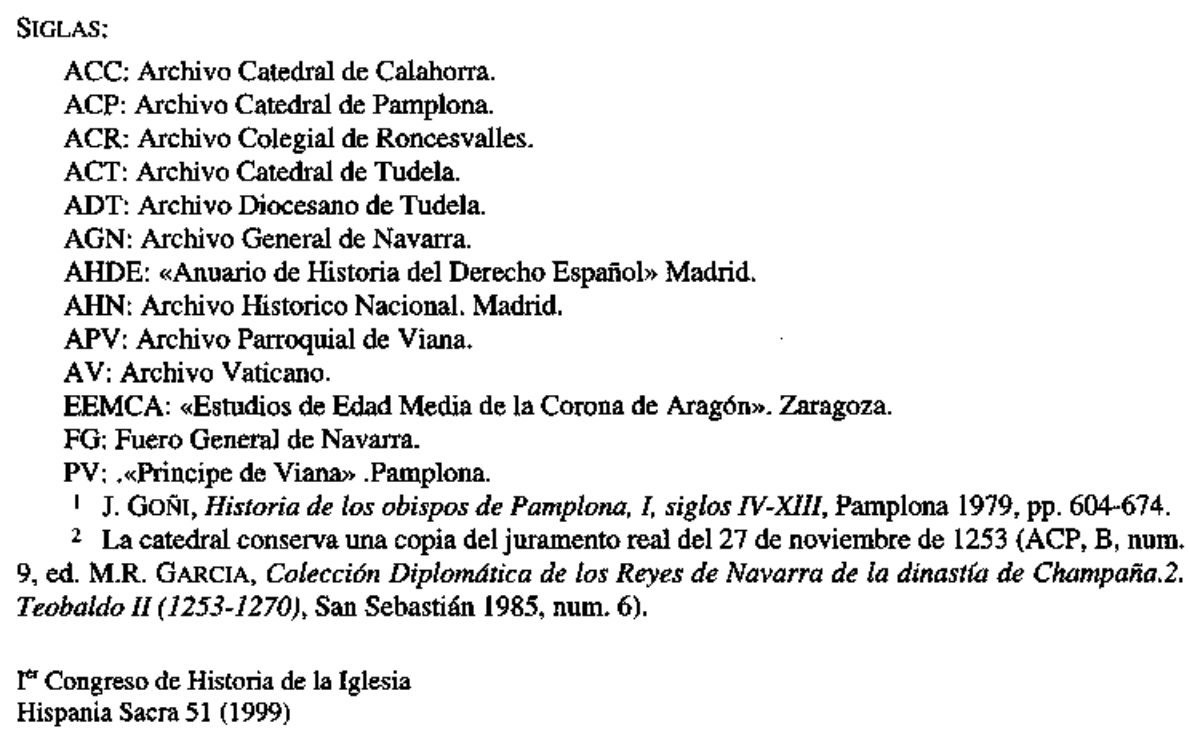


dral ${ }^{3}$, hizo objeto a Santa María de Pamplona de algunas donaciones piadosas. Así es tradición que le regaló un relicario de la Santa Espina, traído de Fran$\mathrm{cia}^{4}$, y cuya fiesta se celebraba ya en Pamplona en el pontificado de Urbano IV 5 . En su testamento, expedido en Cartago en $1270^{6}$, el monarca legó 180 sueldos anuales de renta para una capellanía, a percibir sobre el peaje de Pamplona el 29 de septiembre. Esa suma representaba una renta de seis dineros diarios. Además el capellán recibiría otros veinte sueldos anuales para vestidos, y 200 más a modo de pagas extraordinarias en las fiestas de San Miguel, Navidad, Pascua y la Magdalena, a razon de 50 sueldos en cada una de esas fechas. Si el capellán no cumplia «honesta y limpiamente» con su obligación, el rey, de acuerdo con el obispo, podría reemplazarlo. En caso de enfermedad el propio capellán podría designar un sustituto. El cabildo recibiría en el aniversario del rey una pitanza de cien sueldos, que se cobrarían sobre el peaje de la ciudad.

La manda dirigida a la catedral es la más importante de las establecidas en el testamento real, después de la del hospital de Roncesvalles. El hospital de Santa María, dependiente de la catedral, recibió un legado de 60 sueldos,para pitanza de frailes, sororas y enfermos, en una única entrega para celebrar el primer aniversario del rey. En la rendición de cuentas de los albaceas en 1280 , no figura el abono de estos 60 sueldos 7 .

La catedral conserva dos documentos expedidos por Jaime I el 4 de abril de 1257. El primero es la declaración de las cortes de Lérida en favor de los privilegios de la iglesia, manifestando que la concesión por parte de ésta de una ayuda para gastos de defensa del reino, no produciría perjuicio alguno ${ }^{8}$.Ordenaba seguidamente a sus oficiales declarar públicamente en la diócesis de Pamplona que observarían lo que el monarca había garantizado en las cortes ${ }^{9}$. El 1 de

3 Veánse las bulas papales que concedían al obispo el honor de ungir y coronar al rey de Navama en R. GARCIA, «La Curia Pontificia y la Corona de Navarra a mediados del siglo XIII», Hispania Christiana. Estudios en honor del Prof. Dr. José Orlandis Rovira, Pamplona, 1988, pp. 397-398.

4 C. GarCIA GAINZA y C. HEREDIA (Orfebrería de la catedral y del museo diocesano de Pamplona, Pamplona, 1978, p. 48-49), en su descripción estilística del relicario del Santo Sepulcro de la catedral, lo identifican con el regalado por San Luis a Teobaldo con ocasión del matrimonio de éste. Posteriormente en el Catálogo, de la exposición de Orfebreria de Navarra de 1986, (p. 27-28), C. HEREDIA retrasa la fecha del magnífico relicario pamplonés a los años finales del siglo XIII.

5 Véase nota 12

6 M. R. GarcIA, Colección, num. 88.

7 ACP, B, num. 43, cit. J. GoÑI, Catálogo del Archivo Catedral de Pamplona, I. (829-1500), Pamplona 1965, num. 732.

8 ACP, V Episcopi,. 1, f. 336r.-v.; ed. F.A. TEJADA, Colección de cánones y de todos los concilios de la iglesia de España y de América, VL, Madrid 1859, pp.384-386.; cit. J. GoÑ1, Catálogo, num. 626.

9 ACP, V Episcopi, 1, f. 336v. Cit. J. GoÑ , Catalogo, num. 627. 
noviembre de 1270 Alfonso X recibía bajo su protección a la catedral y en especial a sus bienes en Guipúzcoa ${ }^{10}$.

La mayor parte de las indulgencias están dirigidas a la iglesia de San Martín de Uncastillo, cuyo claustro se estaba edificando entre 1264 y 1268. Dos son de Clemente IV y el resto, hasta nueve, de diversos prelados ${ }^{11}$. Urbano IV concedi6 indulgencias a los que visitaran la catedral en la fiesta de la Espina ${ }^{12}$ y a los que hicieran limosnas para la fábrica de la iglesia ${ }^{13}$.

La mitad de los documentos de índole económica que se conservan en el Archivo catedralicio se refieren a las iglesias dependientes de la mitra en Uncastillo. ${ }^{14} \mathrm{El}$ resto se reparten por igual entre donaciones o compraventas que afectan al cabildo y dotaciones de aniversarios ${ }^{15}$.

b) Santa María de Tudela .

La iglesia colegial de Tudela, dependiente del obispado de Tarazona, ocupa una privilegiada posición en el reino, ya que su única vinculación con dicha sede son las cuartas episcopales que paga al prelado ${ }^{16}$.

El rey expidió un sólo documento a su favor: la orden dada en 1256 al baile de Tudela de pagar a dicha iglesia el diezmo de todas las heredades reales en la ciudad $^{17}$. En su testamento Teobaldo dejó 50 sueldos sobre el peaje de Tudela para su aniversario, a repartir entre los miembros del cabildo que asistieran al coro ese día, quinientos sueldos para la obra de la iglesia y veinte sueldos anuales sobre el peaje de Tudela para celebrar la fiesta de Santa Ana. Esta

\footnotetext{
10 ACP, B, num. 10. Cit. J. GoNı, Catálogo, num. 682 y Los obispos, p. 652.

1 I Clemente IV: 21 de diciembre de 1267, ACP, V Episcopi, 1, f, 250v., cit. J. GoÑl, Catálogo, num. 666; 15 de enero de 1268, ACP,V Episcopi, num. 11, orig., cit J. GoÑ], Catálogo, num. 668. Prelados: arzobispo de Burdeos, 18 de agosto de 1264, ACP, V Episcopi , num 1, f, 336v,; arzobispo de Santiago, 21 de enero de 1268, ACP, V Episcopi, num. 10; arzobispo de Bari, 6 de abril de 1267, ACP, V Episcopi, num. 1, f. 336v.; obispo de Lucca, 16 de abril de 1268, ACP, V Episcopi, num. 1, f. 337r.; obispo de Coimbra, 16 de abril de 1268, ACP, V Episcopi, num. 1, f. 337v.; obispo de Jaén, 20 de abril de 1268, ACP, V Episcopi, num. 1, f. 337r.; obispo don Armingot de Pamplona (1268-1277), ACP, V Episcopi, num. 1, f. 350 v., cit J. GoÑl, Catálogo, nums. 653, 663, 669, 670, 671, 672 y 673.

12 ACP, Fábrica, num., 7 (extracto).,cit. J. GoÑI, Catalogo, num. 644.

13 ACP, Fábrica, num. 6, f. 33r. (extracto).cit. J. Gō̄I, Catálogo, num, 650.

14 J. GoÑI, Catálogo, nums. 614, 622, 623, 624, 625, 635, 648, 657 y 664.

15 J. GoÑI, Catalogo, nums. 595, 606, 615, 631, 660, 661, 675, 677, 678 y 683 .

16 Tras un largo pleito entre las dos dí́cesis, en 1143 el obispo de Pamplona cedí al de Tarazona sus derechos sobre Tudela, dándole el rey como compensación la villa de Marcilla. J.M. LACARRA, La iglesia de Tudela entre Tarazona y Pamplona (I119-1123), EEMCA, V, Zaragoza 1952, pp, 417-425.

17 Ed. M.R. GARCIA, Colección, num. 16.

1 Congreso de Historia de la Iglesia Hispania Sacra 51 (1999)
} 
suma se repartiría como la del aniversario ${ }^{18}$.En 1280 los albaceas habían pagado al cabildo 333 sueldos y 4 dineros ${ }^{19}$.

El único privilegio papal que se conserva de esta época es la concesión de Alejandro IV al deán de Tudela de la mitra y el anillo, el 9 de febrero de $1259 .{ }^{20}$ Esta dignidad es, dentro del clero navarro, la que tiene una mayor presencia en la vida política de reino. En 1255 Lope Garceiz figura como miembro del consejo real, sucribiendo los homenajes que siete ricos hombres prestan al rey Teobaldo $\mathrm{I}^{21}$. En cinco de ellos el deán de Tudela es el único navarro, frente a nueve champañeses ${ }^{22}$. En 1256 vuelve a figurar como testigo en dos actas, expedidas por el senescal ${ }^{23}$. En 1269 otro deán, maestre Pedro, era también consejero del senescal ${ }^{24}$. Por último, el deán de Tudela figura en dos bulas de 1259 y 1268 , destinadas a preservar los privilegios pontificios concedidos al rey, en el segundo caso con ocasión de la cruzada ${ }^{25}$.

La importancia del cabildo de Tudela queda puesta de manifiesto en los estatutos que se promulgaron en 1256 sobre el disfrute de prebendas ${ }^{26}$. Por este

\footnotetext{
18 Véase nota 6

19 Véase nota 7

20 ADT, faj. A, B, num. 7. AV, Reg. 25, f. 194, num. 51. Ed. F. ALESON, Anales del reino de Navarra. IV Adiciones, Tolosa 1890, p. 389. Ed. V. de LA FUENTE, España Sagrada, XLIX, Madrid 1865 pp. 434-435, num. 70. Ed. J.V. DIAZ, Memorias históricas de Tudela, Pamplona 1956, pp. 224225. Cit. J. YangUAS, Diccionario histónico político de Tudela, Zaragoza 1828, p. 93 . Cit. J. Yanguas, Diccionario de Antigüedades del reino de Navarra, II, Pamplona 1964 p. 102. Cit. A. POTTHAST, Regesta Pontificum Romanonum inde ab anno post Christum natum MCXCVII ad adnnum MCCCIV, II, Berlin 1875, num. 17444. Cit. P. MADRAZo, Navarra y Logroño, III, Barcelona 1886, p. 375. Cit. M. SAINZ-P. LABORDA, Apuntes tudelanos, I, Tudela 1913, p. 8. Cit. F. FUENTES, Catálogo de los Archivos eclesiásticos de Tudela, Tudela 1944, num. 1139. Cit. Ch. BOUREL DE LA RONCERE, P. de LOYE, P. de Cenival y A. Coulon, Les Registres d'Alexandre IV, III,París 1953, num. 2820. Cit. J. GoÑ, «Regesta de bulas de los archivos navarros (1198-1417)», Anthologica Annua, X, Roma 1962, p. 318, num. 196. Cit .L.M. MARIN, Historia de la villa de Tudela, Tudela 1978, p. 304.

21 AGN, Comptos, caj.2, num. 93, 94, 113, 98, 99, 95 y 96, ed. M.R. GARCiA, Archivo General de Navarra (I253-1270). Tomo II. Comptos y Cartularios Reales, San Sebastín 1996, num. 19, 20, $23,24,25,26$ y 27.

22 M. R. GARCfA, Teobaldo II de Navarra (1253-1270), Gobiemo de la monarquia y recursos financieros, Pamplona 1986, pp. 88-89.

23 AGN, Comptos, caj. 2, num. 92, ed. M.R. GARClA, Archivo, num. 32 y AMP, caj. 7, num. 40, ed. J.M. LACARRA-A.J. MARTIN DuQUe, Fueros de Navarra. 1 . Fueros derivados de Jaca, 2, Pamplona, Pamplona 1975, num. 40.

${ }_{24}$ AHN, Navarra, leg.668, num. 15, ed. S. GARClA, El Gran Priorado de Navarra de la Orden de San Juan de Jerusalén, II, Pamplona 1957, num. 414.

25 AGN, Comptos, caj. 4, num. 20 y 21, ed. M.R. GARCiA, Archivo, num. 42. y AGN, Comptos, caj. 5, num. 51, ed. M.R. GARClA, Archivo, num. 72.

2625 de mayo de 1256., ACT, caj. 4, let. E, num. 3, cit. F. FueNTES, Catálogo, num. 302 ; cit. J. GONI, Alejandro IV y la universidad proyectada por Teobaldo II en Tudela, (1259)., PV, XVI, 1955, p. 50 y La formación intelectual de los navarros en la Edad Media, EEMCA, X, Zaragoza 1975, p. 153.
}

$I^{\text {er }}$ Congreso de Historia de la Iglesia Hispania Sacra 51 (1999) 
documento se sabe que la iglesia de Tudela, que contaba con maestrescuela, enviaba a sus miembros a formarse fuera del reino, de acuerdo con lo dispuesto por Honorio $\mathrm{III}^{27}$. Tales canónigos podrían gozar de vestuario como los residentes en Tudela.

Tudela sostuvo dos pleitos conocidos en este reinado: el del deán Lope Arceiz con el cabildo y tesorero sobre las ofrendas de la iglesia y el del deán con Rodrigo Sánchez, señor de Murillo de las Limas, sobre los diezmos de la iglesia de esta localidad ${ }^{28}$.

Se conocen dos concordias: la del cabildo de Tudela con el Hospital de San Juan de Jerusalén sobre la capellanía y diezmos de Calchetas y Pedriz, y con el municipio sobre asuntos comunes en Murchante ${ }^{29}$.

Otro nutrido grupo de documentos conservados en la catedral no hace referencia directa a ésta. Se trata de once ventas entre particulares, dos donaciones familiares y una permuta ${ }^{30}$. Hay que destacar en este grupo las seis compras y tres cesiones al censo del portero real Pedro de Morentin, realizadas a título personal, y que permiten adivinar la próspera situación económica de este funcionario, con heredades en los términos de Tudela, Arguedas y Barillas ${ }^{31}$. Cabe reseñar asimismo en 1270 un reparto de hacienda entre los miembros de la familia Baldovín ${ }^{32}$, la más destacada de la ciudad ${ }^{33}$.

27 El legado Juan Halgrin de Abbeville presidió en Lérida un concilio provincial el 29 de marzo de 1229, disponiendo que dos canónigos de cada catedral cursaran estudios de Teología (P. SAINZ DE BARANDA, Espafia Sagrada, XLVIII, Madrid 1862, p. 310),

28 Deán y cabildo: 27 de noviembre de 1258 , ACT, caj. 15, let. S, num. 2, cit. F. FuENTES, Catálogo, num. 313; deán y señor de Murillo: 1255, ADT, faj. D. num. 32, cit. F. FuENTES, Catálogo, num 1138.

29 Hospital: 24 de noviembre de 1254, ACT, caj. 30, let. C, num. 7.; ed. S. GARCIA, El Gran Priorado, II, Pamplona 1957. num. 369.; cit. F. FUENTES, Catálogo, num. 294. Municipio: 6 de julio de 1255, ADT, faj. D, num. 15, cit. F. FuENTES, Catálogo, num. 1137.

30 Ventas de 1256, 1257 (tres documentos ), 1259 (tres documentos), 1260, 1261, 1263 y 1266; donaciones de 1260 y 1262 (dos documentos) y permuta de 1270 .

31 Compró heredades en Tudela en 1259 (viña en Bubierca y heredad en monte de Cierzo) 1260 (heredad en Lobera), 1261 (viña en Armachal) y 1263 (viña en Arnachal); cedió al censo heredades en Arguedas (1263 y 1265) y cambió una casa por otra en Arguedas en 1270. Las dos cesiones al censo se realizan en iguales condiciones: se entrega para plantar una viña cuyos frutos percibe el cultivador hasta que transcurridos 4 años se parte. Después el arrendatario cultiva toda la heredad pero sólo paga censo por la mitad que le ha conrespondido. Este sistema de explotación «ad plantandun» se registra también en el patrimonio de la catedral (C. ORCÁSTEGUI, La iglesia colegial de Santa Marfa la Mayor de Tudela durante los reinados de Sancho VI «el Fuerte» y Teobaldo I, EEMCA, IX, Zaragoza 1973, pp. 490-491).

3227 de marzo de 1270, ACT, caj.35, leg.7, num. 10, cit. F. FUENTES, Catálogo, num. 344.

33 Gil Baldovín, Juez de fuerzas por Tudela en 1254 y testigo del tratado de Monteagudo con Aragón en 1254, era alcalde en 1268. Miguel Baldovín figura como testigo de tres juicios de fuerzas de Tudela en 1254 y como justicia y baile entre 1265 y 1268. Ponce y Guillén Baldovín aparecen

I" Congreso de Historia de la Iglesia Hispania Sacra 51 (1999) 


\section{c) San Miguel de Aralar}

El antiguo monasterio de San Miguel de Aralar se hallaba vinculado al chantre de Pamplona desde 1206, cuando el obispo don Juan de Tarazona, al crear esta dignidad, le señalo las rentas y propiedades de la vieja abadía ${ }^{34}$. Según Mariano Arigita, San Miguel y el monasterio de Zamarce pasaron a ser propiedades de la iglesia catedral y al no residir sus abades en el monasterio, desapareció la regla monástica. Zamarce fue una casa de recreo de los chantres y en San Miguel se estableció una cofradía de clérigos y legos, aunque administrada con independencia de la chantría ${ }^{35}$.

Durante el reinado de Teobaldo II ocuparon el cargo de chantre:

a) Don Iñigo de Sotirana que expidió tres documentos relativos al patrimonio de San Miguel: un contrato de arriendo de una heredad en Ilardia con Iñigo López de Ocue (febrero de '1254) ${ }^{36}$; la compra de una viña en Urrutia propiedad de Juan de Artazco (6 de agosto de 1255) ${ }^{37}$ y el acuerdo con los collazos de San Miguel en Huarte Araquil, conviniendo el pago de tres sueldos anuales por cena y fijando las condiciones en que se debía abonar la pecha (28 de abril de 1257$)^{38}$. Murió antes de 1268, un 27 de febrero según el Obituario de la catedral ${ }^{39}$.

b) Don Jimeno López de Luna, que el 2 de enero de 1268 cedía en arriendo una heredad en Ubani a Lope Sanz de Ubani ${ }^{40}$. En 1269 fue ascendido a prior de la catedral ${ }^{4 !}$.

c) Don Miguel Sánchez de Uncastillo, que el 16 de septiembre de 1269 figura en un documento de La Oliva, como juez árbitro del pleito entre el monasterio y los vecinos de Castelliscar ${ }^{42}$.

\footnotetext{
como testigos en el juicio de fuerzas de Soto Ladrón, de la Orden de San Juan, en 1254 y el segundo además en la alianza de Monteagudo. En 1256 Guillén era justicia.

3429 de septiembre de 1206, ACP, I, Cantoris, 37, 46; ed. M. ARIGITA, Historia de la imagen y santuario de San Miguel de Excelsis, Pamplona, 1904, num. 48; cit. J. GoÑI, Catalogo, num. 449.

35 M. ARIGITA (Historia, p. 80) desmiente a MADRAZO (Navarra, II, p. 183) en la opinión de que parte de las rentas de San Miguel fueran desmembradas para crear la nueva dignidad.

36 ACP, I Cantoris, 37, 57; ed. M. ARIGITA, Historia, num. 54; cit. J. GoNI, Catálogo, num. 599.

37 ACP, I Cantoris, num. 37, f. 94, cit. J. GoÑI, Catálogo, num. 617.

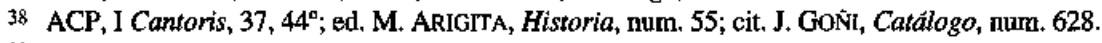

39 Obinuario, f. 2v, ed. Ant. UBLETo, Obinuario de la catedral de Pamplona, Pamplona 1954, p. 10.

40 ACP, I Cantoris, num. 37, $71^{\circ}$; ed. M. ARIGITA, Historia, num, 56; cit. J. GoÑI, Catalogo, num. 667.

41 M. ARIGITA (Historia, p. 85) dice que dejó de ser chantre hacia 1270.

42 AGN, La Oliva, leg. 17, num. 257.
} 
Un sumario de indulgencias concedidas a San Miguel, fechado en 1368, alude a cien días otorgados por Urbano IV (1261-1264). Este documento no se conserva ${ }^{43}$.

\section{DIGNDADES Y RACIONEROS}

El obispo es un señor eclesiástico con propiedades y collazos, que disfruta además los diezmos y primicias de las iglesias rurales que forman parte del patrimonio de la iglesia de Pamplona.

En el siguiente plano cabría colocar a las dignidades de las dos iglesias colegiales de Pamplona y Tudela, que viven bajo la regla de los canónigos San Agustín, la segunda dependiente de la sede de Tarazona ${ }^{44}$.

En la catedral de Pamplona cada una de estas dignidades administra las rentas de una circunscripción de la sede. Así el chantre es abad de San Miguel de Aralar, el arcediano de la Tabla es señor de la población de San Nicolás de Pamplona y el arcediano de la Valdonsella administra las tierras de la diócesis en Aragón. Además figuran como cargos del cabildo el prior, el arcediano de la Cámara, los de Santa Gema, Eguiarte y San Pedro de Usún, el prior de Velate, el hospitalero, el enfermero, el subcapellán, el oficial y el tesorero. El arcediano de la Cámara es el encargado de asignar, junto con el arcediano de la Tabla, las raciones de los beneficiados ${ }^{45}$. En 1254 el cabildo se compone de 31 miembros $^{46}$.

43 ACP, II Cantoris, num. 1, ed. M. ARIGITA, Historia, num. 74.

44 Véase la nota 16. Desde 1193 el cabildo tudelano elegía al prior, que a su vez nombraba a las demás dignidades: sacristán, chantre y portero. El obispo de Tarazona se limitaba a confirnar los cargos (C. ORCASTEGUI, La iglesia, p. 82).

45 El arcediano de la Cámara compartía este cometido con el arcediano de la Tabla. A los dos se dirigió el papa para pedirles que asignaran beneficios eclesiásticos: Al arcediano de la Cámara a favor de Pedro Jiménez el 22 de junio de 1264 (AV, Reg. 29, f. 185, num. 854, cit. J. GUIRAUD, Les Registres $d$ 'Urbain IV, III, Paŕs 1901, num 1804); al arcediano de la Tabla en favor de Jimeno Jiménez el 23 de mayo de 1264 (AV, Reg. 29, f. 182v. num. 835, cit. J. GuIRAUD, Les Registres, III, num. 1785). He aquí la lista de ocupantes documentados de las principales dignidades: prior, Lope Sánchez (12541255 y 1267) y Jimeno López de Luna (1269); arcediano de la Tabla, Pelegrín de Eusa (1254-1259); chantre, Iñigo de Sotirana (1254-1257), Jimeno López de Luna (1258) y Miguel Sánchez de UncastiIlo (1269); arcediano de la Cámara, Romeo de Gazólaz (1267); enfermero, Martín Pérez (1254); tesorero, Miguel Pérez de Legaria (1267-1269); hospitalero, E. Ibáñez (1254-1257); arcediano de Valdonsella, Jimeno López de Luna (1254-1259); arcediano de Eguiarte, Tomás de Estella (12541259); arcediano de San Pedro de Usún, Tomás (1254); arcediano de Santa Gema, Pedro de Sotés (1254-1270); prior de Velate, Martín Jiménez de Mutilva (1254); subcapellán, Jimeno (1255); oficial, Navarro (1255-1256) y Pedro Pérez (1259-1264). El orden de preeminencia de las dignidades figura en los Apuntes del prior Martín de Argaiz del siglo XVII (f. 11). En esta relación el chantre ocupa el octavo lugar, pero según M. ARIGITA (Historia, p. 81) en la Edad Media le correspondía el tercero.

46 El 9 de noviembre, cuando el cabildo ratificó por escrito el arbitraje acordado entre el obispo y Sancho de Antillón sobre los diezmos de Ruesta, formaban parte del mismo el prior, los arcedianos de

Ir Congreso de Historia de la Iglesia

Hispania Sacra 51 (1999) 
Para la época que me ocupa se conservan dos documentos con normas dictadas por el obispo para los racioneros de su jurisdiscción. El primero de ellos de 1263, va destinado a los de San Martín de Uncastillo, disponiendo que sólo pudieran ser recibidos como talès los subdiáconos, o los que, al menos, tuvieran la edad competente para dicha ordenación ${ }^{47}$. El segundo estatuto de 1265 se refiere a la observancia de la regla por los capitulares pamploneses, poniendo coto a los desórdenes introducidos en la vida del cabildo, y dictando un interesante reglamento sobre la confesión ${ }^{48}$.

En Tudela la más alta dignidad del cabildo es el deán que usa mitra y anillo por especial privilegio del papa ${ }^{49}$. Se encuentran citados asimismo el subdeán, el chantre, el sacristán y el maestrescuela ${ }^{50}$.

A las dignidades siguen los canónigos racioneros, con derecho a una porción de las rentas en forma de alimento y vestido. Muchos de ellos no eran presbíteros. Existirían racioneros en todas las iglesias con rentas suficientes: se conocen los casos de Viana, Puente la Reina, Zufía y Falces. Los estatutos de estos beneficiados eran fijados por la autoridad eclesiástica de la que dependían: el obispo de Calahorra, el obispo de Pamplona y la Orden de San Juan respectivamente en los tres primeros casos citados. Falces tenía 25 porcioneros. De ellos tres eran capellanes y otros tres vicario, sacristán y escribano ${ }^{51}$. En Viana había entre sus dos iglesias un total de 53 beneficiados ${ }^{52}$. Los racioneros intervenían en la elección del rector de su iglesia. Asi parece desprenderse de las cesiones al rey de derecho de patronato que hacen los concejos de Miranda,Sesma y Falces.

la Tabla, Valdonsella, Santa Gema y San Pedro de Usún, el chantre, el hospitalero, el enfermero, un licenciado llanado maestre Domingo, el prior de Velate, el vicario de Valtiena y otros canónigos, hasta la cifra de 31. (AFN, Clero, carp. 1425, num. 1, con fecha equivocada del 23 de agosto de 1254).

47 ACP, V Episcopi, 1, f. 336, cit. J. GoǸI, Catálogo, num. 646.

48 ACP, FFF, 57, ed. J. GoNI, «Un interesante decreto episcopal del siglo XIII sobre la confesión», Hispania Sacra, VI, Madrid 1953, pp. 139-149.

49 Véase la nota 20.

so Deán: Lope Arceiz (1255-1260), Pedro Romesa (1265) y Pedro de Pamplona (1270); subdeán, Pelegrín (1264); chantre, Fernando Sánchez (1264-1265); sacristán , Domingo de Aguilar (1268).

s! AGN, Comptos, caj. 1, num. 114, V; ed. M. R. GARCIA, Archivo, num. 61.

52 Las dos iglesias de San Pedro y Santa María fueron unidas en una por don Juan, obispo de Calahorra, el 5 de diciembre de 1329 (APV, perg. num. 7, ed. M.R. GARClA, El Archivo parroquial de Viana (Navarra) hasta 1520, Memoria de Licenciatura inédita, num. 12), de acuerdo con el mandamiento del rey don Felipe de 16 de abril de este año (ibidem, num. 8). Por las procuraciones que ambas iglesias hicieron para este acto de unión, se sabe que Santa María tenía 30 beneficiados, de los cuales uno era diácono. El cura rector era Juan Sánchez (inserto en el documento de 5 de diciembre de 1329, ed. R. Garcia, El Archivo parroquial, num. 11). En San Pedro había 23 beneficiados. Uno de ellos era el abad de Longar, aldea agregada a Viana al fundarse esta villa. El cura rector se llamaba Pedro Sánchez (inserto en el documento de la unión, 7, ed. R. GARCIA, El Archivo, num. 10). 
Los beneficios eclesiásticos eran a menudo recompensas concedidas por el rey a sus servidores. Así en 1262 Urbano IV escribió a la reina Isabel, pidiéndole en agradecimiento a sus regalos, el nombre de dos clérigos a los que ella quisiera favorecer con alguna prebenda ${ }^{53}$.

Se conocen dos estatutos de racioneros: el de Zufía, acordado con el Hospital en $1257^{54}$ y el de Santiago de Puente la Reina, dictado por el arcediano de la Cámara de Pamplona en $1267^{55}$.

En ambos se establece la cuantía de las raciones de comida, la cual podía hacerse dentro o fuera de la abadía. El segundo caso sería, seguramente, el más frecuente. El estatuto de Zufía no establece distinción entre las raciones según el lugar en que se consumieran. Se entregaba a cada racionero un pan, que era la vigésima parte de un robo de trigo ${ }^{56}$, y la cuarta parte de un carapito de vino. Se precisaba que la bebida había de ser la mitad de mosto y la otra mitad de primer pie, es decir de lagar, A este vino se le añadiría menos de una cuarta parte de agua. La porción extraordinaria en pan y vino de los racioneros de Puente es parecida a ésta: cada uno percibía cuatro libras menos un cuarterón de pan y la cuarta parte de un carapito ${ }^{57}$. Desde la vendimia hasta Pascua, la mitad de vino sería mosto y la otra mitad de lagar y desde Pascua a la vendimia, vino normal con un tercio de agua. En este caso la cantidad de pan y vino fijada se aplicaba a las raciones que se consumían fuera de la abadía. Si los racioneros comían dentro, se les daría simplemente «complimento de pan et de vino».

Las raciones de carne y pescado variaban según los días de la semana y el calendario litúrgico. Los de Puente tenían derecho los domingos martes y jue-

53 AV, Reg. 27, f. 34v., num. 1, ed. J. GutRaud, Les Registres, I, París 1899, p. 38-39, num. 142. Hay noticias de la mediación del rey de Navarra para la concesión de otras prebendas: a Pelegrín, subdeán de Tudela, de otra dignidad en Tudela, excluida el deanato (29 de febrero de 1264, AV, Reg. 29, f. 134v., num. 501, cit J. GIRAUD, Les Registres, III, París 1901, num. 1451); a Pedro Jiménez de Aibar, arcediano de Calahorra, de otra dignidad sin cura de almas (4 de julio de 1264, AV, Reg. 29, f. 321 v.,num. 1695, cit. J. GUIRAUD, Les Registres, III, num. 2643); a dos clérigos del obispo de Calahorra como canónigos de Calahorra (9 de agosto de 1264, AV, Reg. 29, f. 329v., num. 1760, cit. J. GUIRAUD, Les Registres, III, num. 2709).

54 AHN, Navarra, leg. 681, num. 78, ed. S. GARCIA, El Gran Priorado, II, num. 376. Los racioneros eran seis.

55 ACP, Cámara, 34, num. 1, cit. J. GoÑI, Catálogo, num. 662.

$56 \mathrm{El}$ robo tiene $22 \mathrm{kgs}$, así que cada pan era de $1.100 \mathrm{grs}$. La porción de vino era de $2 \% 94$ litros. Del robo đe trigo se hacían 20 panes, pero puesto que los racioneros eran seis y con el abad y los tres frailes de San Juan sólo sumaban diez, ignoro para qué se destinaban los otros 10 restantes los días que no eran de adviento y cuaresma y que por tanto sólo se hacía una comida. Es posible que se hiciera limosna con ellos.

57 Cada libra tiene 372 grs., (J. ZABALO, La administración del reino de Navarra en el siglo XIV, Pamplona 1973, p. 232) y el cuarterón sería la cuarta parte. El carapito tiene 1177 litros. Las raciones serían, pues, de 1395 gramos de pan y 2'94 litros de vino.

$I^{\text {sr }}$ Congreso de Historia de la Iglesia

Hispania Sacra 51 (1999) 
ves a un dinero y medio para carne (tres meajas). Los lunes, miércoles, viernes y sábados, a los que comieran en la abadía se les daba tres dineros «por cocina». En Zufía no se precisa cuál era la vianda de estos cuatro días. Para los domingos, martes y jueves se fijaban dos dineros para carne o pescado. Las fiestas más importantes eran objeto de raciones especiales. En Puente, si las festividades de los apóstoles, de los evangelistas, de la Virgen, de la Transfiguración y de determinados santos ${ }^{58}$ caían en alguno de los cuatro días en que se daban tres dineros, se añadían tres meajas para carne o pescado. También en las vigilias de las principales fiestas ${ }^{59}$, en los lunes de las tres Pascuas, y en los domingos de Adviento y Cuaresma se daba la misma cantidad. Finalmente en las grandes solemnidades ${ }^{60}$, se doblaba la ración de came o pescado. Una excepción eran los días de Cuaresma en que la porción era de cuatro dineros diarios, ya que eran fechas de abstinencia y el pescado era más caro que la carne $^{61}$. En Zufía en las fiestas señaladas ${ }^{62}$ y en los tres días siguientes a cada Pascua, cada racionero recibía dos dineros más. En Adviento y Cuaresma se entregaban dos «conduchos».

En Zufía y Puente los racioneros enfermos percibían sus porciones como si ejercieran su ministerio. En el primer lugar, además de los cinco racioneros reglamentarios, había otro de gracia, que sólo recibía un dinero en lugar de dos como sus compañeros. El estatuto de Zufía proporciona además normas sobre la designación de los racioneros. Corría ésta a cargo de tres labradores, tres infanzones y el abad. Los electores juraban designar al «más dreiturero que podrán al lur çient» y el elegido que «sería leal en dito et en feito enta lo Hospital de San Johan». En la abadía residían tres frailes de la Orden que, apor-

58 Eran estos San Juan Bautista, San Lorenzo, Santa Catalina,San Nicolás y la Invención de la Santa Cruz.

59 Apóstoles, Navidad, Ramos, Pascua de Cuaresma, Ascensión, Pascua de Pentecostés, Asunción y Todos los Santos.

60 Tres Pascuas, Epifanía, Purificación, Camestolendas, Ascensión, Santiago, Asunción, San Miguel y Todos los Santos

61 Una libra de pescado en Castilla costaba entre 2 y 5 dineros y un cabrito se podía comprar por 18. Teniendo en cuenta que la libra de pescado tiene 16 onzas y que cada onza equivale a 287 dgms., el kilo de cabrito costaba unos 2 dineros y el de pescado de 4 a 10 dineros (J. GONZALEZ, Reinado y diplomas de Femando III, I, Córdoba 1980, pp. 474-475) .En Navarra la libra de pescado tenía 18 onzas (J. YANGUAS, Diccionario de Antiguedades, II, p. 416 y J. ZABALO, La administración, p. 232).

621 de enero, 6 de enero, 2 de febrero, 25 de marzo y fiestas de San Felipe y Santiago (3 de mayo), Quirico y Julita (13 de junio), San Juan Bautista (24 de junio), San Pedro y San Pablo (29 de junio), Santiago (25 de julio), Transfiguración (6 de agosto), San Lorenzo (10 de agosto), Asunción (15 de agosto), San Bartolomé (24 de agosto), Natividad de la Virgen ( 8 de septiembre), San Mateo (21 de septiembre), San Miguel (29 de septiembre), San Servando y San Germán (23 de octubre) San Simón y San Judas (28 de octubre). Todos los Santos (1 de noviembre), San Andrés (30 de noviembre) y las tres Pascuas. 
tando los correspondientes dineros, podían comer con los racioneros los domingos, martes y jueves.

Por último, y aunque no se trate de un estatuto, cabe citar el acuerdo de Roncesvalles con el ex-rector de San Esteban de Castellón en Sangüesa. La casa de Roncesvalles acordó en 1260 dar a Lope García vitaliciamente veinte cahíces de trigo y dos porciones como las que correspondían a los racioneros de dicha iglesia. Este documento revela que los beneficiados de San Esteban de Castellón percibían, como los de Zufía, dos raciones en Adviento y Cuaresma ${ }^{63}$.

En lo que se refiere a vestido, se conserva un reglamento dictado por el deán de Tudela para los canónigos de dicha iglesia, que fija la asignación en dos dineros diarios,tanto para los beneficiados presentes como para los ausentes por razón de estudios y los que recibían doble ración diaria de comida. Del estatuto quedaban excluidos el deán y el obispo de Tarazona ${ }^{64}$.

\section{EL PATRONATO DE LAS IGLESIAS}

El derecho de patronato de una iglesia rural corresponde desde antiguo al señor de la villa, ya fuera el rey, un noble o una institución eclesiástica. ${ }^{65}$ En el caso de las villas aforadas parece que era el concejo, seguramente a través de sus autoridades representativas, quien elegía al abad. $\mathrm{Si}$ en la iglesias existían varios clérigos racioneros, estos intervenían también en la designación. Así parece desprenderse de las cesiones al rey del derecho de patronato de Miranda, Sesma y Falces. Los fueros de estas localidades y los de Baigorri y Lerín no aluden a este derecho que, al parecer, ejercían los $\operatorname{concejos}^{66}$.

63 Convenio del 9 de julio de 1260, ACR, Abadías, num. 11, ed. V. VILlabrigA, Sangüesa, ruta compostelana, Sangüesa 1962, num. 23 e I. OstolAZA, Colección Diplomática de Santa María de Roncesvalles (1127-1300), Pamplona 1978, num. 177.

64 ACT, caj. 4, let. E, num. 3. El documento del 25 de mayo de 1256 lleva inserta la autorización del cabildo al deán, chantre y maestrescuela para proveer lo relativo a vestuario, expedida el 6 de junio. Alguna de las dos fechas está ,pues, errada. Me inclino a creer que es la primera, habiéndose escrito $8^{\circ}$ kalendas de junio por $8^{\circ}$ kalendas de julio. Se trataría entonces del 24 de junio.

65 El derecho de patronato se explica como una tendencia a la intervención laica en la administración de las iglesias y tenía su origen en el sistema de iglesias propias (M. TORRES, El origen del sistema de iglesias propias, AHDE, V, Madrid 1928, pp. 145-146 y 159-163).

66 Fueros de Baigorri de 18 de julio de 1234 (AGN, Cart. I, p. 275-276, ed. M. MARTIN, Colección Diplomática de los reyes de Navarra de la dinasta de Champaña I. Teobaldo I (1234-1253), San Sebastián 1987, num. 2), de Lenín de septiembre de 1211 (AGN, Cart. 1, p. 277-278, ed. L.J. FORTUN, Colección de "fueros menores»de Navarra y otros privilegios locales (II), PV, XLII, 1982, p. 991-992, num. 79) y de Miranda de octubre de 1208 (AGN, Comptos, caj. 5, num. 65, ed. L.J. FORTUN, Colección, p. 980-981, num. 70).

$\mathbf{I}^{\mathrm{rr}}$ Congreso de Historia de la Iglesia Hispania Sacra 51 (1999) 
El Fuero General establecía una limitación al ejercicio del patronato. Tanto si era villa de realengo, como de orden o enfranquecida, el elegido debía ser vecino o hijo de vecino, quedando excluídos aquellos que hubieran adquirido la vecindad durante la última enfermedad del abad difunto, en la expectativa de poder sucederle. En la siguiente ocasión podían ser ya elegidos ${ }^{67}$. El abad contribuía como un vecino más a las cargas comunales por la heredad que llevaba aneja la abadía ${ }^{68}$.

A juzgar por la documentación relativa al derecho de patronato, que se conserva para el reinado de Teobaldo II, en las villas que tenían comunmente el «ius patronado» o el derecho de presentar abades, se suscitaban discordias con grave daño espiritual y material, que en algún caso llegaba hasta el homicidio. En 1264 seis localidades, cuatro de ellas en la merindad de Tudela, cedieron al rey el patronato de sus iglesias: Miranda, Sesma, Falces, Lerín., Baigorri y Cáseda ${ }^{69}$.Todas ellas lo venían ejerciendo independientemente, salvo Miranda y Cáseda, que ya lo compartían con el monarca ${ }^{70}$. Los correspondientes documentos acreditativos fueron expedidos por el concejo bajo la fórmula «conceialment $\gg^{71}$. o especificando la composición en clérigos, labradores y caballeros e infanzones en el caso de Cáseda ${ }^{72}$. En el de Falces los labradores «comunalment» redactaron un documento y los clérigos otro, posiblemente porque el número de éstos es daba cierta entidad como grupo ${ }^{73}$. Los respectivos notarios de los concejos escribieron y certificaron las cartas. La similitud de términos entre los documentos, demuestra que estas poblaciones habían llegado a un acuerdo con el rey en fechas muy próximas.

67 FG, 3.1.1

68 Ibidem.

69 S6́lo tres llevan la fecha completa: los de Miranda y Cáseda ( 8 de febrero de 1264) y el de Sesma (3 de marzo de 1264). Los demás están fechados en 1263, pero sin duda se trata de documentos expedidos por la misma fecha de los anteriores, es decir febrero o marzo del año de la Encarnación o de la Pascua de 1263, que es 1264. MORET alude a otra cesion de patronato, la de Peralta, que no se ha conservado (Anales, IV, Tolosa 1890, p. 339).

70 De Miranda se conservan dos documentos: uno extenso con fecha del 8 de febrero de 1264 y otra redacción abreviada en el año de Señor de 1263. Sólo el primero alude a la intervención de rey, junto con el concejo, en la elección. Lo que cedieron, pues, los de Miranda, era el uso del derecho de patronato por el rey, sin contar con la villa.

71 Cesión de Baigorri: AGN, Comptos, caj. 1, num. 114 III, ed. M.R. GARCIA, Archivo, num. 58. Cesión de Lerín: AGN, Comptos, caj. 1, num. 114 II, ed. M. R. GARCíA, Archivo, num. 62.

72 Cesiones de Miranda: AGN, Comptos, caj. 1, num. 114 VI y VII, ed. M. R. GARClA, Archivo, nums. 51 y 59. Cesión de Sesma: AGN, Comptos caj. 1, num. 114 I, ed. M. R. GARCía, Archivo, num. 55. Cesión de Cáseda: AGN, Comptos, caj. 1, num. 114 VIII, ed M. R. GARClA, Archivo, num. 52.

73 Labradores: AGN, Comptos, caj. 1, num. 114 IV, ed. M.R. GARClA, Archivo, num.60 . Clérigos: AGN, Comptos, caj. 1, num. 114 V, ed. M. R. GARClA, Archivo, num. 61. Tres clérigos eran capellanes y había también vicario, sacristán y escribano. Los demás eran simples racioneros.

$\mathrm{I}^{\mathrm{er}}$ Congreso de Historia de la Iglesia Hispania Sacra 51 (1999) 
Se ignora el papel que Teobaldo II ejerció en esta solución, que evitaba las disputas entre los vecinos, se convertía en un instrumento de recompensa regia para servicios cortesanos. De hecho varios clérigos del rey, funcionarios de la cancillería o de la administración central, se titulan abades. Seguramente el monarca fue respetuoso con el requisito de vecindad que establecía el Fuero, pero al hacer recaer el cargo en gentes a su servicio, la residencia de estos abades en su parroquia rara vez sería efectiva. De entre estos nombres cabe destacar en primer lugar al abad de Abaurrea, administrador de Ultrapuertos, y a los notarios reales, el abad de Legarda y el abad de Arróniz ${ }^{74}$. El Registro de Comptos de 1266 menciona también al abad de Bigüézal, que fue mensajero del rey con ocasión de la guerra de Gascuña y cobró 50 sueldos por sus servicios y al de Asiain, que llevo dineros al senescal a la misma hueste ${ }^{75}$.

Con posterioridad a 1264 no se conservan más noticias sobre el derecho de patronato que la reseña de un pleito en la abadía de Falces, que figura en el Registro de $1266^{76}$.

En Ultrapuertos el rey tenía, se ignora desde cuando, derechos de presentación. En 1264, con ocasión de la aprobación de una permuta hecha con Roncesvalles, cedió a esta casa el patronato de las iglesias de San Esteban de Baiguer y de San Pedro y Santa Eulalia de Arbeloa ${ }^{77}$. Sin embargo, dos años después, percibía el rey el tributo de la iglesia de San Esteban, que con la cuarta de la de $\mathrm{NaOz}$, suponía 140 sueldos $^{78}$. Este hecho indicaría que las rentas que correspondían al rey en dichas abadías no pasaron a Roncesvalles.

En el caso de las iglesias dependientes de la mitra pamplonesa, cabe destacar los intentos de D. Pedro Jiménez de Gazolaz por reforzar su intervención en la provisión de dignidades. Las cesiones espontáneas de patronato al obispo fueron, en cambio, menos relevantes. Sólo se documentan en una ocasión ${ }^{79}$.

El alcalde y las autoridades de la villa franca, además del derecho de patronato, parecen tener cierta intervención en la administración de sus iglesias. Así cuando en 1264 el obispo de Calahorra falló el pleito entre Santa María de Viana y las aldeas de Bargota y Goraño, la sentencia fue pronunciada «con

74 El abad de Legarda y el abad de Arróniz percibian gajes de la corte (Registro, f. $41 \mathrm{v}$.) y una cantidad fija para ropa y bestias (f. 56v. y 57r.) que ascendía a 380 sueldos. Veease el epígrafe Los clérigos en M. R. GARCfA, Teobaldo II de Navarra. Gobierno de la monarquía y recursos financieros, Pamplona, 1985, pp. 107-110.

75 Registro, f. $45 \mathrm{v}$. y $47 \mathrm{r}$.

76 «Per lo despens des alcaldes, que anauan per lo playt de la abbadia de Falces, 39 s. por mandament del senescal» (Registro, f. 12v.).

7 Ed. M. R. GarCiA, Colección, num. 27.

78 Registro, f. $29 \mathrm{r}$.

79 J. GoÑI, Los obispos, pp. 637-638.

$\mathrm{I}^{\text {er }}$ Congreso de Historia de la Iglesia Hispania Sacra 51 (1999) 
consentimiento del alcalde, et de los jurados et de los otros omes buenos» de la villa, que pusieron su sello en el acta correspondiente ${ }^{80}$.

\section{DIEZMOS Y PRIMICIAS}

Los diezmos y primicias de los fieles corresponden al señor de la villa. En las villas de francos quedarían para la iglesia.

El pago de los diezmos era objeto de múltiples controversias entre las iglesias locales o entre las iglesias y las entidades de las que dependían. Además del pleito del deán de Tudela con Rodrigo Sánchez por los diezmos de Murillo de las Limas, ya mencionado ${ }^{81}$, cabe reseñar otros:

a) Entre dos instituciones importantes

La encomienda de San Juan en Tudela y el Cabildo de esta ciudad se disputaban los diezmos y otros ingresos de dos aldeas de la Orden: Calchetas y Pedriz. El compromiso de 1254 estableció que la iglesia de Tudela ejercería el derecho de patronato en Calchetas y percibiría los diezmos de todos los parroquianos. La Orden de San Juan pagaría también los diezmos de sus heredades, pero podría gozar de las rentas de sepulturas, cediendo al cabildo de Tudela la tercera parte de los legados de los difuntos. Los derechos de bautismo y las ofrendas serían también disfrutadas por los frailes en nombre de la iglesia de Tudela. Como reconocimiento le darían un aúreo alfonsino de oro. Luminarias y aniversarios quedarían íntegros en manos de la Orden de San Juan ${ }^{82}$. Un acuerdo parecido se firmó al año siguiente entre la Orden y el cabildo de Calahorra, acordándose que la encomienda sanjuanista en Casanueva daría a la catedral la mitad de los diezmos de las heredades que los collazos de la Orden dependientes de Casanueva labraban en territorio de la diócesis calagurritana ${ }^{83}$.

b) Entre una institución y la iglesia que depende de ella.

En 1260 el Hospital acordaba con el rector de San Andrés de Sangüesa que en adelante la Orden renunciaría a la designación de racioneros y a otros derechos a los bienes de la iglesia. El abad sería sostenido por la Orden, que se reservaba el señorío y «algún reconoscimiento que ayamos «, según lo que habla sentenciado el chantre de Tudela en un documento que no se ha conser-

\footnotetext{
${ }^{80}$ Documento inserto en la sentencia definitiva del oidor de Calahorra del 23 de noviembre de 1329 (APV, perg. num. 6, ed. M. R. GARCiA, El Archivo parroquial, num. 2).

81 Véase la nota 28.

8224 de noviembre de 1254, ACT, caj. 30, et. C, num. 7, ed. S. GARCí, El Gran Priorado, II, num. 359, cit. F. FUENTES, Catálogo, num. 294.

8317 de agosto de 1255, ACC, sig. 319, ed. S. GARCía, El Gran Priorado, II, num. 384.
} 
vado $^{84}$ En 1264 el obispo Bibiano de Calahorra dictaminaba que los clérigos de Santa María de Viana estaban obligados a colocar un capellán en las aldeas de Bargota y Goraño y a enviar otro que le ayudara en las tres Pascuas del año. A cambio los habitantes de Bargota y Goraño darían sus diezmos a la iglesia de Viana ${ }^{85}$.

c) Entre dos iglesias locales

En 1257 el arcediano de Berberiego, mediante una sentencia, repartía los diezmos de las heredades que los de Labraza y Viana labraban en Valdevarón y que habían correspondido a la desaparecida iglesia de San Martin de Tidón. Se hizo el deslinde de Valdevarón, y se estableció que la mitad de los diezmos de lo que que los de Labraza labraran en terreno de jurisdicción de Viana sería para la iglesia de San Pedro de esta villa, y los de Viana a su vez darían a San Miguel de Labraza la mitad de los diezmos de lo que labraran en la feligresía de Labraza ${ }^{86}$.

\section{CONCLUSIONES}

$\mathrm{El}$ análisis cuantitativo y cualitativo de las fuentes manejadas revela diferencias entre los cabildos de las catedrales. La información es más abundante para la iglesia de Pamplona, sede de la cabeza del reino. Cuenta con tres documentos reales de los monarcas de Aragón y Castilla, frente al único que conserva Tudela, si bien éste expedido por Teobaldo II. Las difíciles relaciones que la Corona sostuvo a lo largo del siglo XIII con el obispo de Pamplona, en particular con el enérgico don Pedro Jiménez de Gazólaz, motivan, quizá, la ausencia de privilegios reales. Con todo, el monarca navarro destinó a la catedral la manda más cuantiosa de su testamento, después de la de Roncesvalles.

También en cuanto a las bulas hay notables diferencias entre Pamplona y Tudela, aunque la conservada para esta colegiata, atribuyendo a su deán el uso de la mitra y el anillo como los obispos, es cualitativamente más importante que las de Pamplona, que promocionan obras en iglesias anejas a la catedral. Parece, pues, que a mediados del siglo XIII Tudela estaba tratando de realzar, frente a las mitras de Pamplona y Tarazona, la figura de su deán, que aparece como consejero real y protector de los privilegios concedidos por el pontífice al monarca navarro.El estatuto sobre el disfrute de prebendas por parte de los canónigos tudelanos residentes fuera, manifiesta una apertura exterior del cabildo.

8423 de abril, AHN, Navarra, leg. 698, num. 1, ed. S. GARCfA, El Gran Priorado, II, num. 384.

85 Véase la nota 80.

868 de diciembre, APV, perg, num. 1, ed. M. R. GARCfA, El Archivo parroquial, num. 1.

$\mathrm{I}^{\text {er }}$ Congreso de Historia de la Iglesia

Hispania Sacra 51 (1999) 
Los documentos de índole económica parecen, en cambio, más numerosos en Tudela. Se constata aquí un dinamismo en la gestión del patrimonio y una estrecha relación entre el cabildo y la oligarquía urbana. San Miguel de Aralar, institución dependiente del chantre de Pamplona, concentra una parte sustancial de las actas relativas a la explotación del señorío de la catedral, entre las que destaca un convenio con los collazos de Huarte Araquil.

El número de racioneros no parece guardar relación absoluta con la capacidad económica de la institución. Así frente a los 31 de la catedral de Pamplona, se documentan 25 en Falces y 53 en Viana. De los estatutos de beneficiados conservados, hay que distinguir el de índole disciplinar de 1265 para el cabildo de Pamplona, y los que fijan las porciones propiamente dichas. En este último caso se constata que las asignaciones de pan, vino, came y pescado eran parecidas en cualquiera de las instituciónes patrocinadoras. En todas ellas múltiples fiestas del año eran ocasión de percibir raciones extraordinarias, y estos «conduchos» podían comerse dentro o fuera de la abadía. La cuantía de los mismos induce a pensar que los porcioneros los llevaban a sus casas, donde la familia consumiría el excedente, ya que,especialmente en Adviento y Cuaresma, eran suficientes para al menos dos personas.

La concesión de prebendas por intervención del rey se halla documentada de forma directa en varias ocasiones, y de modo indirecto por la presencia en la corte de abades y rectores en calidad de funcionarios cualificados. No es posible saber hasta qué punto el rey tuvo parte directa o inclusó forzó la cesión del patronato de varios concejos, todos ellos por las mismas fechas, coincidiendo con la presencia del monarca en Navarra.

El nombramiento del abad en las villas francas corresponde al concejo. $\mathrm{Si}$ hay racioneros estos intervienen también en la designación. De acuerdo con el Fuero General, el abad debía ser vecino de la villa.

Un pequeño número de referencias a iglesias dependientes de órdenes religiosas indica que sus clérigos gozaban de estatutos parecidos a los de otras instituciones seculares. 